\title{
Progress on the Design and Fabrication of the MICE Focusing Magnets
}

\author{
D. E. Baynham, T. W. Bradshaw, J. H. Cobb, M A Green Member IEEE, W. W. Lau, S. Q. Yang
}

\begin{abstract}
The Muon Ionization Cooling Experiment (MICE) focusing solenoid magnets focus the muon beam within the MICE cooling channel on a liquid or solid absorber that is within the warm bore of solenoid. The focusing magnet has a warm bore of $470 \mathrm{~mm}$. This magnet consists of two coils 210-mm long that is separated by an aluminum mandrel that is $200 \mathrm{~mm}$ long. Each of the coils has its own leads. The coils may be operated in either the non-flip mode (solenoid mode with both coils at the same polarity) or the flip mode (quadrupole focusing mode where both coils are at opposite polarity). This report describes the focusing solenoid magnet design that will be built by the vendor. The progress on the construction of the first of the focusing magnets will also be discussed in this report. Ultimately three of these magnets will be built. These magnets will be cooled using a pair $1.5 \mathrm{~W}$ (at 4.2 K) pulse tube coolers.
\end{abstract}

\section{Index Terms-Superconducting Focusing Magnet}

\section{INTRODUCTION}

$\mathrm{T}$ he MICE focusing magnet is the magnetic element of the absorber focus coil (AFC) module [1-3]. The AFC module is where muon ionization cooling occurs within the experiment. At the center of the AFC module is absorber that reduces the momentum of the muons in both the longitudinal and transverse direction. The muons are re-accelerated in the longitudinal direction using RF cavities that are within the RF coupling coil (RFCC) module. If after reacceleration there is a net reduction transverse momentum, then there is net cooling. While the absorber is reducing the transverse momentum, scattering of the muons occurs as they interact with the absorber material. The absorber at the center of the AFC module may be either a liquid absorber or a solid absorber. The best absorber material (the material that produces the least amount of scattering) that can be used at the center of the AFC module is liquid hydrogen. Thus the AFC module is designed as a superconducting magnet with a liquid hydrogen absorber at its center.

Manuscript received 20 October 2009. This work is supported by funds from the UK Sciences and Facilities Council. This work was also supported by the Office of Science of the US Department of Energy under DOE contract DE-AC-02-05CH11231.

D. Baynham and T. W Bradshaw are with the Rutherford Appleton Laboratory, Chilton-Didcot, OX11-0QX, UK, J. H. Cobb, W. W. Lau and S> Q. Yang are with Oxford University Physics Department, Oxford OX1-3RH, UK, M. A. Green is with Lawrence Berkeley National Laboratory, Berkeley CA 94720, USA (e-mail: magreen@1bl.gov).
The overall outside diameter of the AFC module (not including the turret for superconducting magnet and absorber services) is $1404 \mathrm{~mm}$. The overall length of the AFC module is limited by the space occupied by the RF cavities in adjacent RFCC modules. When one allows for getting the modules in and out of the experiment, the length of the AFC module is $782 \mathrm{~mm}$. The magnet cold mass, the magnet shields, the magnet insulation, and the liquid hydrogen absorber system is bounded by a cylindrical volume that is $1404 \mathrm{~mm}$ in diameter by $782 \mathrm{~mm}$ in length. The turret above the cylindrical volume contains the coolers, the shield connections, the magnet leads, and the liquid hydrogen absorber liquefaction and cooling system. The position of the coolers and HTS leads within the turret is determined by the stray magnetic field from the magnet when it is operated at its maximum current [4].

The warm bore of the focusing magnet cryostat was set at $470 \mathrm{~mm}$. Within the magnet warm bore is the solid or liquid absorber. The absorber minimum diameter is $350 \mathrm{~mm}$. For a solid absorber this is the minimum diameter of the solid disc. For a liquid hydrogen absorber, the diameter of both types of thin windows was set $350 \mathrm{~mm}$. The liquid hydrogen absorber that is designed to fit into the warm bore of the magnet has an outer diameter of about $400 \mathrm{~mm}$ [5]. This allows for a radial space of $35 \mathrm{~mm}$, which will contain the liquid hydrogen service pipes, a support system and the absorber multilayer insulation. The placement of the absorber within the absorber is shown in Fig 1.

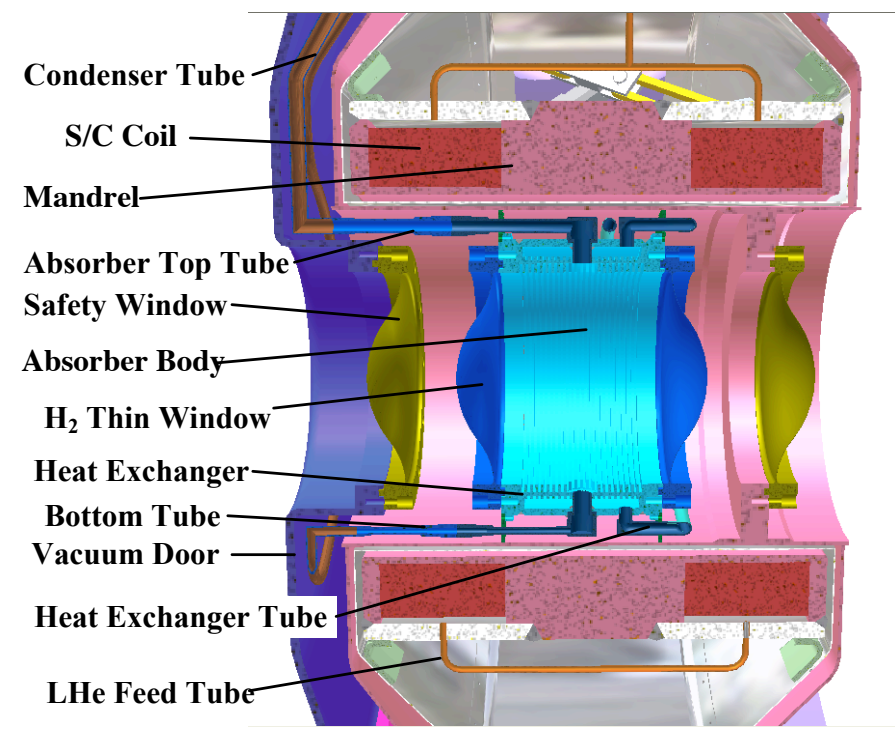

Fig. 1. A three dimensional cross-section of the MICE liquid absorber, its thin windows, the liquid hydrogen feed tubes, and the focusing magnet. 


\section{The Focusing Magnet Design Parameters}

The superconductor for the focusing magnet is somewhat smaller than the conductor proposed for the original focusing magnet design. This conductor selected by the vendor is slightly smaller than the conductor used for the original spectrometer solenoid magnet design. (The original conductor comes from a different vendor.) The focusing magnet uninsulated conductor dimensions are $0.95 \mathrm{~mm}$ by $1.52 \mathrm{~mm}$. The insulated dimensions are $1.00 \mathrm{~mm}$ by $1.57 \mathrm{~mm}$. Like the conductor proposed in the original design, the conductor that will be used has a copper to superconductor ratio of 4 , number of filaments 220 , filament diameter $\sim 41 \mu \mathrm{m}$, and a twist pitch of about $19 \mathrm{~mm}$. The $\mathrm{j}_{\mathrm{c}}$ of the superconductor is greater than $3000 \mathrm{~A} \mathrm{~mm}^{-2}$ at $5 \mathrm{~T}$ and $4.22 \mathrm{~K}$. The measured critical current for the conductor is $>800 \mathrm{~A}$ at $5 \mathrm{~T}$ and $4.2 \mathrm{~K}$. The piece lengths for the conductor are on the short side. As a result, the vendor coil design calls for splices within the coils. The maximum allowable splice resistance is set at $10 \mathrm{n} \Omega$ [6].

Since the conductor critical current is higher than for the original design, there will be small changes in the coil design that will result in a larger temperature margin for the magnet. The magnet quench characteristics will change slightly. The propagation velocities in all directions will be increased about six percent [7]. The hot spot temperature will increase, but the conductor will probably decrease the quench-back time for the coils, once the normal region has been formed [8], [9]. Table I shows the basic design parameters for focusing magnet as the magnet vendor design dictates.

TAble I. The Basic Parameters of the MICE Focusing

\begin{tabular}{|c|c|c|}
\hline Parameter & Non-flip & Flip \\
\hline Warm Bore Radius (mm) & \multicolumn{2}{|c|}{235} \\
\hline Outer Cryostat Radius (mm) & \multicolumn{2}{|c|}{702} \\
\hline AFC Module Length (mm) & \multicolumn{2}{|c|}{844} \\
\hline Magnet Cryostat Length (mm) & \multicolumn{2}{|c|}{745} \\
\hline Cold Mass Length (mm) & \multicolumn{2}{|c|}{690} \\
\hline Number of Coils in the magnet & \multicolumn{2}{|c|}{2} \\
\hline Magnet Coil Length (mm) & \multicolumn{2}{|c|}{210} \\
\hline Coil Separation Distance (mm) & \multicolumn{2}{|c|}{200} \\
\hline Coil Inner Radius (mm) & \multicolumn{2}{|c|}{263} \\
\hline Coil Thickness (mm) & \multicolumn{2}{|c|}{84} \\
\hline Coil End to End Distance (mm) & \multicolumn{2}{|c|}{620} \\
\hline Number of Conductor Layers & \multicolumn{2}{|c|}{76} \\
\hline Number of Turns per Layer & \multicolumn{2}{|c|}{132} \\
\hline Magnet $\mathrm{J}\left(\mathrm{A} \mathrm{mm} \mathrm{mm}^{-2}\right)^{*}$ & 69.8 & 135.4 \\
\hline Magnet Current (A)* & 123.1 & 236.1 \\
\hline Magnet Self Inductance (H) & 148.4 & 106.5 \\
\hline Peak Induction in Coil $(\mathrm{T})^{*}$ & 4.94 & 7.52 \\
\hline Magnet Stored Energy $(\mathrm{MJ})^{*}$ & 1.12 & 2.98 \\
\hline 4.2 K Temp. Margin $(\mathrm{K})^{*}$ & $\sim 2.1$ & $\sim 0.7$ \\
\hline External $\mathrm{B}$ at $\mathrm{R}=0.7 \mathrm{~m}(\mathrm{~T})^{*}$ & 0.12 & $\sim 0.65$ \\
\hline Direction of Field Lines & Axial & Radial \\
\hline Inter-coil Z Force $(\mathrm{MN}) *$ & -0.54 & 3.39 \\
\hline
\end{tabular}

The focusing cold mass support system is designed to carry magnetic forces in the longitudinal direction (along the magnet axis) of $900 \mathrm{kN}$. There has been a change of scope as far as the experiment is concerned. The focusing magnet will have a self-centering support system [3] as does the MICE spectrometer solenoid [10] and as is proposed for the MICE and MuCOOL coupling magnets [11].

The support system proposed by the focusing magnet vendor is a single-band support system. The spectrometer solenoid and coupling magnet use or will use a double-band support system. Fig. 2. illustrates the concept behind the proposed single-band focusing magnet cold mass support system. The focusing magnet vendor proposes to stress the cold mass support bands at a higher stress levels than the support bands for the spectrometer and coupling magnets.

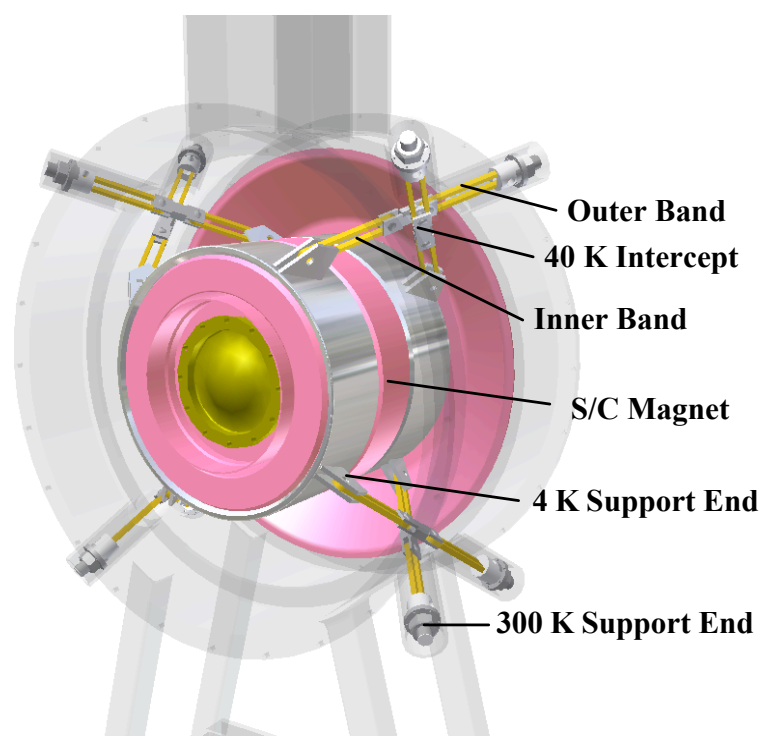

Fig. 2. A Schematic representation of the single-band cold mass support system that is proposed for the MICE focusing magnet.

The focusing magnet will be indirectly cooled using a pair of Cryomech PT415 pulse tube coolers that generate $1.5 \mathrm{~W}$ of cooling at $4.2 \mathrm{~K}$ on the second-stage while generating $50 \mathrm{~W}$ of cooling on the first stage, at a temperature of $55 \mathrm{~K}$. Table II shows the projected heat leaks into the magnet cryostat at $4 \mathrm{~K}$ and $55 \mathrm{~K}$. These heat loads could be low given the experience on other magnets that have been cooled using two-stage coolers. The key is keeping the first stage temperature low.

Fig. 3. shows an exploded view of the AFC module. Included are the magnets components, the absorber, the absorber piping and the absorber cooling components.

TABle II. The Estimated Focusing Magnet Heat LoAdS AT $55 \mathrm{~K}$ AND $4.2 \mathrm{~K}$

\begin{tabular}{lcc}
\hline \hline \multicolumn{1}{c}{ Component } & \multicolumn{2}{c}{ Heat Leak (W) } \\
& @ 55 K & @ 4 K \\
\hline Cold Mass Supports & $\sim 13$ & $\sim 0.62$ \\
Radiation through MLI & $\sim 10$ & $\sim 0.60$ \\
Necks and Instrumentation & $\sim 9$ & $\sim 0.43$ \\
Current Leads & $\sim 50$ & $\sim 0.20$ \\
\hline Total Estimated Heat Leak & $\sim 82$ & $\sim 1.75$ \\
\hline
\end{tabular}




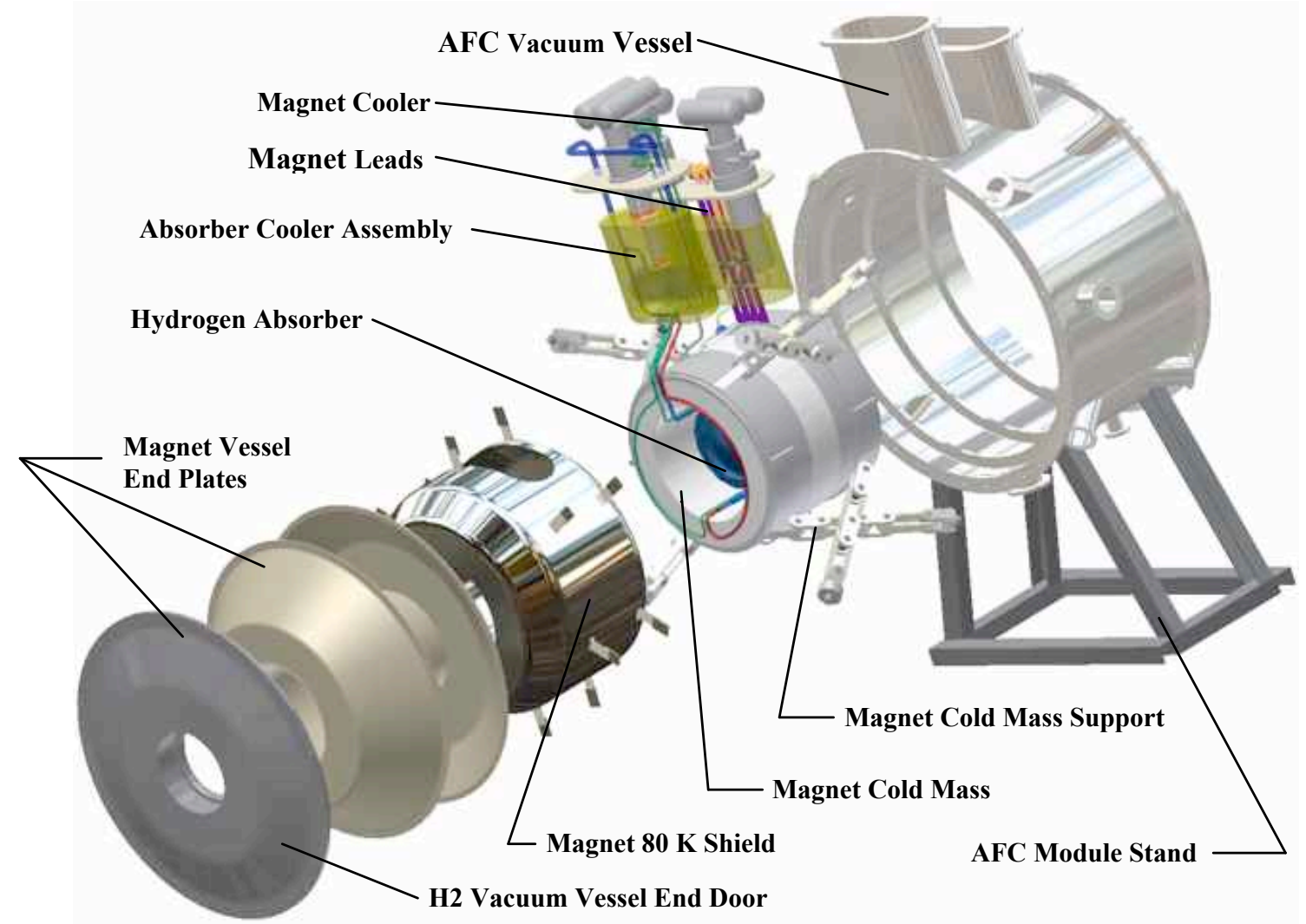

Fig. 3. A schematic exploded view of the AFC module showing the magnet, the magnet coolers, the absorber, and the absorber cooler.

When one looks at Table II one sees that the projected first stage heat load on each cooler is about $41 \mathrm{~W}$. If the first stage heat leaks were $41 \mathrm{~W}$, the stage temperature would be $<50 \mathrm{~K}$. The heat load calculations suggest that the copper leads are the dominant. This heat leak from $293 \mathrm{~K}$ down the copper leads is well understood [12], [13]. While the copper leads represent over sixty percent of the heat load into the first stage, the other heal loads must not be ignored. It is extremely important that the top of the HTS leads be kept below $60 \mathrm{~K}$. Failure to keep the tops of the HTS cold can cause the leads to fail [14].

Heat flow into the $4 \mathrm{~K}$ region is directly affected by the temperature of the cold mass support intercepts, the pipe and instrumentation wire intercepts and the top of the HTS leads. If one looks at these three terms in Table II, one sees that sixty-five percent of the $4 \mathrm{~K}$ heat loads comes from these sources. Conduction heat loads are proportional to the temperature squared [13]. If the $55 \mathrm{~K}$ temperature in Table II is increased to $70 \mathrm{~K}$, the total heat load at $4 \mathrm{~K}$ goes up from $1.75 \mathrm{~W}$ to $2.46 \mathrm{~W}$ w/o considering the extra radiation heating.

The magnet cold mass must be insulated with multilayer insulation (MLI). The MLI protects the cold mass from thermal radiation shine that might occur because of the many holes that will be in the shield. In addition MLI between the shield and the cold mass greatly reduces free-molecular conduction through gas in the vacuum space.

The original magnet design called for the coils to be surrounded by liquid helium. When one combines the magnet with a helium vessel, the pressure vessel code comes into play. As a result, the focusing magnet will be indirectly cooled using helium in tubes attached to the magnet coil cover plates.

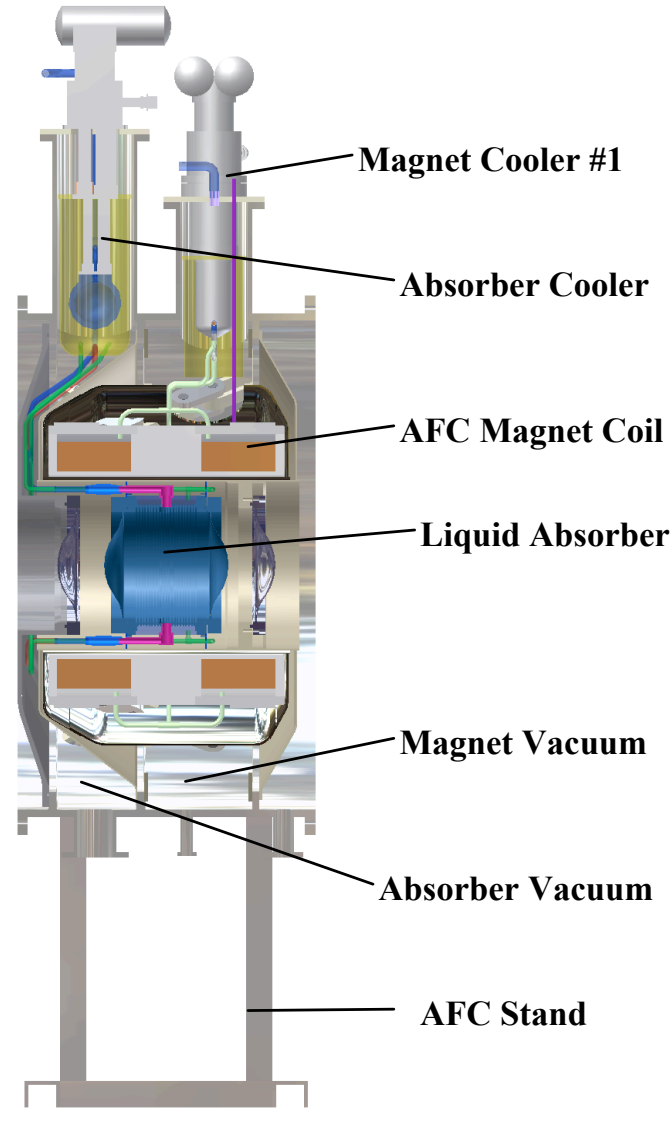

Fig. 4. A cross-section view of the MICE AFC module showing the magnet coils, the liquid absorber, the cryostat vacuum vessel and the coolers. 
Fig. 4. is a cross-section of the magnet through the coils, the magnet turret with its coolers and leads. Fig. 4. shows the magnet cryostat vacuum vessel, the absorber vacuum vessel with its safety windows, and the magnet thermal shield. The absorber cooler, its condenser tank, and the absorber piping are also shown in Fig. 4. The magnet as shown in Fig. 1. and Fig. 4. shows bath-cooled coils. The helium bath in Fig. 4. will be replaced by cooled aluminum closure rings indirectly cooled with liquid helium in tubes.

\section{Progress ON THE Focusing MAgnets}

Construction of the first focusing magnet cold mass has started. The mandrel was fabricated out of a 6061-T6aluminum forging. The cover plates that cover the coils and contain the magnet cooling are also fabricated out of 6061-T6aluminum forgings. Fig. 5. shows the machined mandrel for the first focusing magnet. One end of the mandrel is thicker than the other end. The thicker end of the mandrel will be machined to match the other end of the mandrel after the magnet coils are wound and banded. The machined closure rings will be welded to finished coil assembly. The helium cooling tubes that connect the top and bottom helium tanks are welded to the closure. A separate cool down tube will also be attached to the finished cold mass assembly.

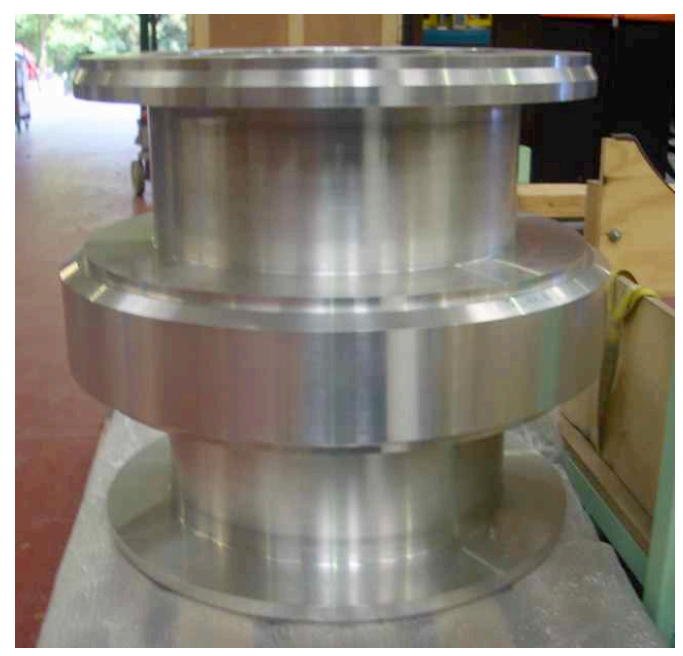

Fig. 5. The machined mandrel for the first focusing magnet.

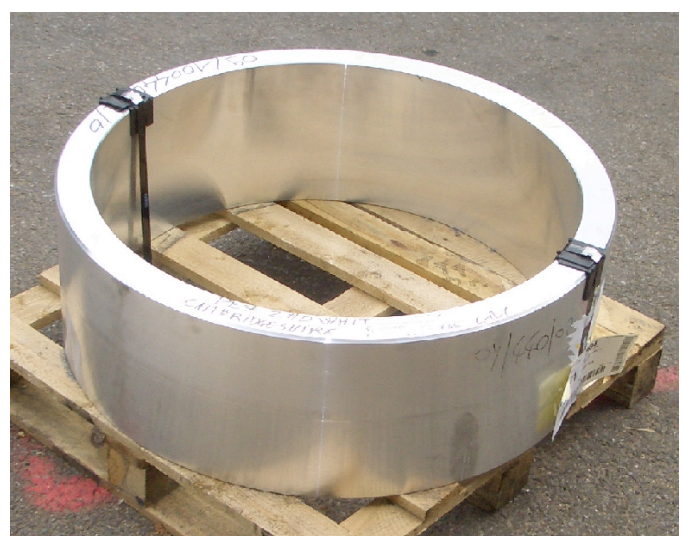

Fig. 6. Focusing magnet closure ring forging.

\section{CONCLUSION}

Tesla Engineering Limited in the UK was selected as vendor for the AFC module in 2007. After a year of detailed engineering by the vendor, fabrication of the focusing magnets has started. The magnet design is based on a conductor with insulated dimensions of $1.0 \times 1.57 \mathrm{~mm}$. The number of turns in the focusing magnet changed along with other magnet parameters. The magnet will be indirectly cooled with helium in tubes. The focusing magnet will use a passive quench protection system based on diodes and resistors across the coil. Quench-back from the 6061-T6 aluminum mandrel will cause both coils in the focusing magnet to quench.

The AFC module may be a challenge for cooling with small coolers. There are two pairs of leads designed to carry $250 \mathrm{~A}$ in a radial magnetic field that approaches $0.3 \mathrm{~T}$ at the top of the HTS leads that are at the highest temperature. Keeping the temperature of the top of the leads at $60 \mathrm{~K}$ or lower will be a challenge given the $50 \mathrm{~W}$ heat load that will come down the copper leads from room temperature.

\section{REFERENCES}

[1] G. Gregoire, G. Ryckewaert, L. Chevalier, et al, "MICE and International Muon Ionization Experiment Technical Reference Document," http://www.mice.iit.edu, 2001.

[2] S. Q/ Yang, M. A. Green, G. Barr, et al, "The Mechanical and Thermal Design for the MICE Focusing Solenoid Magnet System," IEEE Transactions on Applied Superconductivity 15, No. 2, p 1259, (2005)

[3] S. Q. Yang, M. A. Green, W. Lau, et al, "Cold Mass Support System and Helium Cooling System for the MICE Focusing Solenoid," IEEE Transactions on Applied Superconductivity 17, No. 2, p 1251, (2007)

[4] M. A. Green, S. Q. Yang, J. Cobb, et al, "The Effect of Magnetic Field on the Position of HTS Leads and the Cooler in the Services Tower of the MICE Focusing Magnet, IEEE Transactions on Applied Superconductivity 18, No. 2, p 1447, (2008)

[5] D. E. Baynham, P. Bish, T. Bradshaw, et al, "A Liquid Cryogen Absorber for MICE," Advances in Cryogenic Engineering 51, p 1068, AIP Press, Melville NY (2006)

[6] F. Y. Xu, H. Pan, H. Wu, et al, "Measurement of the Resistance and Strength of Conductor Splices in the MICE Coupling Magnets," to be published in Advances in Cryogenic Engineering 55, AIP Press, Melville NY (2010)

[7] M. A. Green and H. Witte, "Quench Protection and Magnet Power Supply Requirements for the MICE Focusing and Coupling Magnets," LBNL-57580, MICE Note 114, http://mice.iit.edu, (2005)

[8] X. L. Guo, F. Y. Xu, L. Wang, et al, "Quench Protection for the MICE Cooling Channel Coupling Magnet", IEEE Transactions on Applied Superconductivity 19, No. 3., p 1360, (2009)

[9] X. L. Guo, M. A. Green, L. Wang et al, "The Role of Quench-back in the Passive Quench Protection of Long Solenoids with Coil SubDivision," submitted to IEEE Transactions on Applied Superconductivity 20, (this publication) (2010)

[10] M. A. Green and S. P. Virostek, "MICE Spectrometer Magnet System Progress, IEEE Transactions on Applied Superconductivity 18, No. 2, $\mathrm{p}$ 933, (2008). A picture of a double band support strut is shown on $\mathrm{p} 936$

[11] H. Wu, X. K. Liu, L. Wang, et al, "Structural Design and Analysis for a Double-Band Cold Mass Support of the MICE Coupling Magnet," to be published in Advances in Cryogenic Engineering 55, AIP Press, Mellville NY, (2010).

[12] M. N. Wilson, Superconducting Magnets, Chapter 11, Oxford University Press, Oxford, UK (1983)

[13] A. M. Kadin, R. J. Webber, and D. Gupta, "Current Leads and Optimized Thermal Packaging for Superconducting Systems on Multistage Coolers, IEEE Transactions on Applied Superconductivity 17, No. 2, p 915, (2007).

[14] S. P. Virostek, M. A. Green, "The Results of Tests of the MICE Spectrometer Solenoids," submitted to IEEE Transactions on Applied Superconductivity 20, (this publication) (2010) 


\section{DISCLAIMER}

This document was prepared as an account of work sponsored by the United States Government. While this document is believed to contain correct information, neither the United States Government nor any agency thereof, nor The Regents of the University of California, nor any of their employees, makes any warranty, express or implied, or assumes any legal responsibility for the accuracy, completeness, or usefulness of any information, apparatus, product, or process disclosed, or represents that its use would not infringe privately owned rights. Reference herein to any specific commercial product, process, or service by its trade name, trademark, manufacturer, or otherwise, does not necessarily constitute or imply its endorsement, recommendation, or favoring by the United States Government or any agency thereof, or The Regents of the University of California. The views and opinions of authors expressed herein do not necessarily state or reflect those of the United States Government or any agency thereof, or The Regents of the University of California. 